\title{
IMPLEMENTASI TUJUAN PENDIDIKAN DALAM MENINGKATKAN HASIL BELAJAR SISWA DI MTs PATRA MANDIRI PLAJU KOTA PALEMBANG
}

\author{
Ulfa Kesuma $^{1}$,Tasman Hamami ${ }^{2}$ \\ ${ }^{1,2}$ UIN Sunan Kalijaga Yogyakarta \\ Email: kesumaulfa@gmail.com ${ }^{1}$, tasmanhamami61@gmail.com²
}

\begin{abstract}
The learning process is a measure of the results of the efforts made by educators and students with all related factors. This study will describe how the implementation of educational goals in improving learning outcomes at MTs Patra Mandiri Palembang City. The research was conducted with a qualitative approach. The subjects of this study were the head of the foundation, the principal, the Islamic education teacher. The method of collecting data with indepth interviews was assisted by the WhatsApp application and document searches and data analysis were carried out using descriptive analytics. The conclusion is that the implementation of MTs Patra Mandiri learning uses a concise curriculum model, namely the compaction of materials and mass. From the assessment of all learning at MTs Patra Mandiri, all problems related to competence. Therefore, these questions can be used as a measuring tool to see the learning objectives. However, there are some problems that have not met the objective criteria of learning because the tool specified is an objective exam. The process of product assessment and assessment is carried out in the learninglearning process (not in the final semester exam). Therefore, the processes and products cannot be carried out regularly to the students for the long term. Based on student scores in the final semester exams, the learning objectives at MTs Patra Mandiri have been achieved. Naturally, students have unique characteristics, namely having individual diversity from one another in various ways. This diversity can be manifested in the diversity of intelligence, talents, personalities, and physical conditions.
\end{abstract}

Keywords: National Education Objectives, Learning Outcomes

Abstrak
Proses pembelajaran merupakan ukuran hasil usaha yang dilakukan oleh
pendidik dan pelajar dengan semua faktor yang berkaitan. Penelitian ini akan 
mendeskripsikan bagaiamana implementasi tujuan pendidikan dalam meningkatkan hasil belajar di MTs Patra Mandiri Kota Palembang. Penelitian dilakukan dengan pendekatan kualitatif. Subyek penelitian ini adalah kepala yayasan, kepala sekolah, guru PAI. Cara mengumpulkan data dengan wawancara mendalam dibantu aplikasi WhatsApp dan penelusuran dokumen dan analisis data dilakukukan dengan deskriptif analitis. Kesimpulnya bahwa dalam pelaksanaan pembelajaran MTs Patra Mandiri menggunakan model kurikulum ringkas, yaitu pemadatan bahan dan masa. Dari segi menilai semua pembelajaran di MTs Patra Mandiri, semua masalah mempunyai kaitan dengan kompetensi. Oleh itu, soal-soal ini dapat dijadikan alat pengukur untuk melihat pencapaian objektif pembelajaran. Walau bagaimanapun, beberapa soal belum sepenuhnya memenuhi tuntutan objektif pembelajaran karena alat penilaian yang digunakan adalah berbentuk ujian objektif. Berdasarkan nilai siswa dalam ujian akhir semester, tujuan pembelajaran di MTs Patra Mandiri telah tercapai. Secara alamiah siswa memiliki sifat unik, yaitu memiliki keragaman individual antara satu dengan yang lain dalam berbagai hal. Keragaman tersebut dapat berwujud keragaman intelegensi, bakat, kepribadian, dan kondisi jasmani.

Kata Kunci: Tujuan Pendikan Nasional, Hasil Belajar

\section{PENDAHULUAN}

Dalam peningkatan ilmu pengetahuan pendidikan sangat berpenran penting dan berpengaruh besar baik diwilayah formal maupun informal demi membentuk manusia yang berkualitas. Untuk menciptakan manusia yang berkualitas, tentu diperlukan beberapa indikator dan tujuan yang dapat dicapai oleh anak dalam proses pembelajarannya. Tujuan pendidikan inilah yang akan memberikan arah dan mendorong keberhasilan siswa dalam proses pembentukan kepribadian dan menambah ilmu pengetahuan peserta didik tanpa mengesampingkan unsur-unsur yang lain dalam pendidikan.

Tujuan pendidikan dalam pembukaan UUD 1945 ialah untuk mendidik kehidupan bangsa, di mana kecerdasan bukan hanya dalam kecerdasan intelektual tetapi kecerdasan keseluruhan yang memiliki 
makna yang lebih luas seperti yang dinyatakan dalam UU No. 20 tahun 2003 Pasal 3 Sistem Pendidikan Nasional yang berbunyi:

"Pendidikan bertujuan untuk mengembangkan potensi pelajar agar mereka menjadi manusia yang percaya dan takut kepada Tuhan Yang Maha Esa, berakhlak mulia, sihat, berpengetahuan, berkebolehan, kreatif, berdikari, dan menjadi warganegara yang bertanggungjawab dan bertanggungjawab.".

Tujuan pendidikan yang tertera didalam UUD, telah dipertimbangkan secara matang agar tujuan tersebut dapat terealisasi untuk kemajuan pendidikan di Indonesia dengan begitu harapannya pendidikan dapat menciptakan setiap pribadi menjadi manusia yang berguna dan dapat memberikan pengaruh yang baik terhadap manusia boleh bertanggungjawab terhadap diri mereka sendiri dan orang lain serta memiliki watak yang memiliki keahlian atau sering yang disebut dengan skill. ${ }^{1}$ Maka dari itu, setiap peserta didik diminta untuk dapat mempertanggung jawabkan apa yang telah mereka kerjakan sebagai bagian dari tujuan pendidikan nasional.

Kemajuan dan perkembangan pendidian merupakan salah satu faktor keberhasilan suatu Bangsa. Beberapa Negara menjadi contoh yang telah mmeiliki kemajuan didalam dunia Pendidikan, misalnya Firlandia, Amerika maupun Eropa. Hal ini tidak dapat dilihat dari berbagai data yang menunjukkan bahwa Negra-Negara tersebut dapat menciptakan peserta didik yang dapat diserap oleh banyak lapangan pekerjaan dengan mudah karena telah menonjolkan keunggulan dalam dunia pendidikan seperti model pembelajarannya, mendorong anak untuk menciptakan karya atau hasil-hasil penelitian 2001).

1 Madyo Eko Susilodkk, Dasar-Dasar Pendidikan (Semarang: Effha, 
produk-produk dan hasil akhir proses pembelajaran. ${ }^{2}$ Berangkat dari beberapa pengalaman Negara-negara tersebut, hasil akhir proses pembelajaran merupakan suatu indikator atau tujuan yang sangat diharapkan untuk dapat tercapai sebagai standar kelulusan setiap peserta didik.

Hasil belajar merupakan penggabungan dari kata "Hasil" dan "Belajar". Jika dipadukan, Hasil pembelajaran adalah tindakan penilaian yang dapat mendedahkan aspek proses pemikiran (domain kognitif) dan dapat mendedahkan aspek psikologi yang lain, iaitu aspek nilai atau sikap (domain afektif) dan aspek kemahiran (domain psikomotor) yang wujud dalam diri pelajar. Ini bermaksud bahawa melalui hasil pembelajaran, gambaran holistik mengenai pencapaian pelajar dapat didedahkan setelah melalui pembelajaran.

Tujuan pendidikan sangat menjurus kepada hasil yang dicapai oleh setiap peserta didik. Setiap lembaga pendidikan pasti memiliki standar kelulusan tersendiri meskipun secara keseluruhan berkiblat pada Tujuan Pendidikan Nasional. Sebagaimana Tujuan dan Misi dari MTs Patra Mandiri Palembang yang akan menjadikan siswa bebas dari buta aksara Al-Qur'an, menerapkan kemahiran / pekerjaan yang berpotensi, berakhlak mulia, sihat, berpengetahuan, berkebolehan, kreatif, berdikari dan mampu bersaing dengan sekolah lain dan menjadikan pelajar dapat mengambil bahagian dalam komuniti dengan baik. ${ }^{3}$

${ }^{2}$ Munirah, "Sistem Pendidikan Di Indonesia: Antara Keinginan Dan Realita," Jurnal Auladuna 2, no. 2 (2015): 233-45.

${ }^{3}$ Dokumen MTs Patra Mandiri Kota Palembang. 
Melihat dari tujuan dan misi dari pada MTs Patra Mandiri ini, terdapat interkoneksi antara tujuan lembaga dan tujuan pendidikan Nasional. Namun, untuk melihat apakah tujuan pendidikan tersebut tercapai atau tidak, dapat diukur dengan keberhasilan belajar atau hasil belajar siswa. Berangkat dari penjelasan diatas, dapat disimpulkan bahwa tujuan pendidikan sangat penting bagi setiap lembaga pendidikan.

Penelitian yang dilakukan oleh I Gusti Lanang Agung Parwata (dalam Jurnal Penyelidikan dan Pembangunan Pendidikan Jilid 2 Nombor 1, April 2008) yang bertajuk Aplikasi Model Pembelajaran Langsung Berbantukan Media VCD untuk Meningkatkan Aktiviti Pelajar dan Hasil Pembelajaran di Kelas Atletik I. Hasil yang diperoleh adalah penerapan Model Pembelajaran Langsung yang dibantu VCD dapat meningkatkan aktiviti pembelajaran dalam pembelajaran I atletik bagi pelajar kelas C semester pertama Prodi Pendidikan Jasmani pada tahun akademik 2006/2007.4

Penelitian T.H. Agustanti, Pelaksanaan Kaedah Inkuiri untuk Meningkatkan Hasil Pembelajaran Biologi, Jurnal Pendidikan Sains Indonesia, Vol.1 No.1 tahun 2012, hlm. 16-20. Dari hasil pelaksanaan pembelajaran biologi dengan mempraktikkan penyelidikan (inkuiri), penulis membuat kesimpulan berikut: (1) Pembelajaran dengan meneliti (inkuiri) di kelas VIIE SMP N 2 Wonosobo dapat menjadikan pelajar aktif, bersemangat, bersemangat, berpartisipasi dan

4I Gusti Lanang Agung Parwata, "Penerapan Model Pembelajaran Langsung Berbantuan Media VCD Untuk Meningkatkan Aktivitas Dan Hasil Belajar Mahasiswa Pada Perkuliahan Atletik I," Penelitian dan Pengembangan Pendidikan 2, no. 1 (2008). 
mengambil berat tentang perkembangan teknologi . (2) Pembelajaran dengan meneliti (inkuiri) di kelas VII E SMP N 2 Wonosobo dapat menaikan pencapaian hasil pembelajaran pelajar serta menjadikan proses belajar mengajar menjadi lebih kondusif. ${ }^{5}$

Adapun penelitian Purpose Of The Brief bahwa Praktik pembinaan kritis terakhir mencakup pengembangan hubungan guru dan murid yang positif, juga disebut sebagai aliansi. Aliansi yang kuat antara guru dan murid membentuk dasar yang kokoh didalam proses pembelajaran sebagai landasan pembinaan yang produktif. ${ }^{6}$

Studi penelitian saat ini berusaha untuk menyoroti pentingnya tujuan pembelajaran berbasis standar dalam meningkatkan dan meningkatkan kualitas pendidikan, dan mendeskripsikan model yang dirancang untuk menganalisis hasil pembelajaran dari program pendidikan guru. Beberapa metode penelitian digunakan dalam merancang dan menguji model yang dikembangkan untuk mengukur hasil belajar dalam program pendidikan guru Kuwait. Hasil memberikan informasi penting tentang pencapaian tujuan pembelajaran di berbagai tingkatan. Kesimpulan dan rekomendasi membahas hasil dan menawarkan wawasan tentang penelitian lanjutan di masa depan dalam pengaturan pendidikan tinggi. ${ }^{7}$

${ }^{5} \mathrm{~T}$ H Agustanti, "Implementasi Metode INquiry untuk meningkatkan Hasil Belajar Biologi," Jurnal Pendidikan IPA Indonesia 1, no. 1 (2012): 16-20.

${ }^{6}$ Purpose Of The Brief, "Effective Coaching: Improving Teacher Practice and Outcomes for All Learners," WestEd 1, no. 1 (2005): 1-17.

7 Zaid Al-shammari, "Implementation Of Standards-Based, Learning Objectives-Enhanced Student Learning And Achievement Via A Designed Analysis Model For Learning Outcomes ( Amlo ) In A Teacher Education Program In Kuwait: A Preliminary Analysis" 16, no. 1 (2006): 1-5. 
Dengan melihat daripada visi misi dan tujuan pendidikan di MTs Patra Mandiri, maka hasil belajar menjadi tolak ukur keberhasilan pada lembaga pendidikan. Oleh karena itu, penulis melakukan mini riset tentang implementasi tujuan pendiidkan dalam meningkatkan hasil belajar siswa pada MTs Patra Mandiri. Berdasarkan uraian diatas maka penulis akan menguraikan bahwa Bagaimana Implementasi Tujuan Pendidikan dalam meningkatkan hasil belajar di MTs Patra Mandiri?

\section{METODE PENELITIAN}

Penelitian ini termasuk penelitian studi lapangan yang bersifat kualitatif dimana penelitian yang akan menjawab suatu permasalahan secara mendalam dalam konteks waktu dan situasi yang bersangkutan, dilaksanakan secara fakta dan alami sesuai kondisi rill dilapangan tidak adanya manipulasi, serta data yang dikemas merupakan data kualitatif. ${ }^{8}$

Sumber data dalam penelitian ini adalah ketua yayasan, kepala sekolah, guru PAI MTs Patra Mandiri serta dokumen yang berkenaan dengan permasalahan penelitian ini. Metode pengumpulan datanya melalui observasi, wawancara mendalam, dan dokumentasi. Sedangkan analisis data dalam penelitian ini menggunakan teknik Data Reduction (Data Reduksi), Display (Data Penyajian), dan Verifikasi (Ditarik Kesimpulan). Penelitian ini dibantu dengan menggunakan metode e-learning (online) dan aplikasi WhatsApp. Kaedah ini digunakan untuk mengkaji dan mendapatkan data

${ }^{8}$ Burhan Bungin, Penelitian Kualitatif (Jakarta: Kencana, 2007). 
mendalam tentang pelaksanaan pendidikan dalam meningkatkan hasil pembelajr di MTs Patra Mandiri.

\section{HASIL PENELITIAN}

\section{Analisis Implementasi Tujuan Pendidikan dalam Meningkatkan Hasil Belajar di MTs Patra Mandiri}

Hasil pembelajaran adalah corak tindakan, nilai, pemahaman, sikap, penghargaan, dan kemahiran. ${ }^{9}$ Hasil pembelajaran adalah hasil interaksi antara proses pengajaran dan pembelajaran. Dari sudut pandangan guru, tindakan pengajaran diakhiri dengan penilaian hasil pembelajaran atau penilaian. Dari sudut pandangan pelajar, hasil pembelajaran adalah akhir pemotongan dan puncak proses pembelajaran (Hasil Pembelajaran). ${ }^{10}$

Hasil pembelajaran ini berkaitan dengan pencapaian dalam memperoleh kebolehan sesuai dengan tujuan tertentu yang dirancang. Matlamat adalah sesuatu yang diharapkan dapat dicapai setelah perniagaan atau aktiviti selesai, sementara pendidikan digunakan sebagai perniagaan atau aktiviti yang memproses melalui beberapa tahap dan tahap yang mempunyai tujuan. Oleh itu, tugas utama guru dalam aktiviti ini adalah merancang instrumen yang dapat mengumpulkan data mengenai kejayaan pelajar dalam mencapai matlamat pembelajaran. ${ }^{11}$

9 Agus Suprijono, Cooperative Learning: Teori $\mathcal{E}$ Aplikasi Paikem (Yogyakarta: Pustaka Pelajar, 2009).

10 Zainal Arifin, Pengembangan Managemen Mutu Kurikulum Pendidikan Islam, Cet. I (Yogyakarta: DIVA Press, 2012).

${ }^{11}$ Bukhari Umar, Ilmu Pendidikan Islam (Jakarta: Amzah, 2011). 
Berdasarkan data yang ada seorang guru dapat mengembangkan dan meningkatkan program pembelajaran menjadi lebih menarik. Dalam menentukan hasil pembelajaran selain menentukan instrumen, perlu juga merancang bagaimana menggunakan instrumen dan kriteria kejayaannya. Ini perlu dilakukan, kerana dengan kriteria yang jelas dapat ditentukan apa yang harus dilakukan oleh pelajar dalam mempelajari isi atau bahan pembelajaran. ${ }^{12}$

Instruktur yang efektif biasanya bangga dengan interaksi siswa yang positif di dalam dan di luar kelas, memberikan umpan balik yang cepat, dan mendorong kerja tim di antara siswa. Guru yang paling berpengaruh juga memperoleh dan menerapkan umpan balik yang konstruktif, dan menggunakan teknik yang berbeda untuk mendorong pembelajaran aktif yang berorientasi pada lingkungan siswa menjadi pemikir mandiri, mandiri, dan kritis. ${ }^{13}$

Implementasi Tujuan pendidikan didalam MTs Patra Mandiri Kota Palembang diterapkan baik dalam proses pembelajaran, penerapannya setiap program-program yang diadakan maupun evaluasi yang akan mengukur tingkat keberhasilan belajar siswa. Hal ini ada kaitannya dengan pengertian kurikulum, dimana kurikulum merupakan usaha menyeluruh yang dilakukan oleh suatu lembaga pendidikan untuk mewujudkan hasil yang diinginkan baik dalam

12 Wina Sanjaya, Strategi Pembelajaran (Jakarta: Kencana, 2007).

${ }^{13}$ Allison Paolini, "Enhancing teaching effectiveness and student learning outcomes," The Journal of Effective Teaching 15, no. 1 (2015): 20-33, http://search.ebscohost.com/login.aspx?direct=true\&db=eue\&AN=102152590 \&site $=$ ehost-live\&scope $=$ site . 
sekolah maupun diluar sekolah mengingat bahwa MTs Patra Mandiri banyak melaksanakan kegiatan-kegiatan diluar jam aktif belajar didalam kelas.

\section{Perencanaan, visi misi, tujuan}

Perencanaan merupakan hal yang sangat penting didalam lembaga pendidikan, dengan adanya perencanaan setiap program dapat tersusun dengan baik dan dapat direalisasi sesuai dengan tujuan yang diinginkan.Perencanaan merupakan upaya membuat kegiatan agar lebih fokus, terarah dalam mencapai tujuan. Menurut Sa'ud \& Makmun

Perancangan adalah serangkaian aktiviti proses untuk menyiapkan keputusan tentang apa yang diharapkan akan terjadi (peristiwa, keadaan, suasana, dll.) Dan apa yang akan dilakukan (intensifikasi, keberadaan, penyemakan, pengubahsuaian, penggantian, penciptaan, dll.). Rangkaian proses aktiviti dijalankan agar matlamat ini dapat direalisasikan pada masa akan datang. ${ }^{14}$

Dalam proses pencapai tujuan, terdapat beberapa unsur yang tertera didalam pesernacanaan, diantaranya adalah (1) sejumlah kegiatan yang ditetapkan sebelumnya, (2) adanya proses, (3) hasil yang ingin dicapai, dan (4) menyangkut masa depan dalam waktu tertentu..$^{15}$ Perencanaan yang diterapkan di MTs Patra Mandiri diantaranya Realisasi Tata Tertib Lembaga dan penyusunan RPP sebagai pedoman guru dalam menyampaikan materi kepada peserta didik.

Untuk melihat realisasi dari pada perencanaan yang terdapat di MTs Patra Mandiri Kota Palembang, peneliti mencoba menghubungi Wakil Kurikulum yaitu ibu Hj. Asnah HNmelalui via

14 Sa'ud Dkk, Perencanaan pendidikan (Bandung: PT. Remaja Rosdakarya, 2014).

${ }^{15} \mathrm{H}$. Usman, Manajemen teori, praktik, dan riset pendidikan. (Jakarta: PT. Bumi Aksara, 2008). 
telepon mengingat diadakannya Lockdown pada wilayah Palembang karena menyebarnya wabah virus corona di Indonesia:

"pada awalnya kami membuat perencanaan dengan menetapkan beberapa peraturan-peraturan mbak, agar tujuan dan visimisi kami dapat terealisasi dengan baik. Kami juga meminta setiap guru dapat membuat RPP sebagai pengembangan daripada silabus agar memudahkan dalam penyampaian materi kepada peserta didik mengingat bahwa Tujuan pendidikan kita sangat jelas ya didalam UUD, sehingga hal itu yang akan kita capai dengan diiringi oleh visi dan misi yang jelas didalam MTs Patra Mandiri."16

Dari penjelasan selaku wakil kurikulum MTs Patra Mandiri tersebut dalam mewujudkan tujuan pendidikan sesuai dengan tujuan pendidikan Nasional, Patra Mandiri membuat sejumlah Tata Tertib yang harus ditaati oleh seluruh warga MTs agar proses pembelajaran dapat berjalan dengan baik. Berikut Tata Tertib MTs Patra Mandiri Kota Palembang:

a. Semua pelajar akan berada di sekolah selewat-lewatnya pada 06.40 WIB

b. Pelajar yang tidak hadir dibenarkan jika (1) Penyakit / keperluan sangat penting, (2) Memasuki setelah mendapat kebenaran mesti membawa surat dari guru piket, (3) Pelajar dilarang meninggalkan pelajaran, (3) Pelajar yang sudah merasa sakit sehingga tidak pergi ke sekolah

c. Taat pada guru, saling menghormati

d. Tanggungjawab menjaga kebersihan, keselamatan, ketenteraman sekolah

e. Pelajar dikehendaki melakukan aktiviti ekstrakurikular sekurang-kurangnya 1 jenis aktiviti

f. Meninggalkan waktu kelas tanpa kebenaran

g. Memakai perhiasan dan pakaian yang berlebihan yang tidak sesuai dengan keperibadian bangsa

h. Merokok di dalam dan di luar kelas

16 Hasil wawancara dengan Dra. Hj. Asnah HN, "selaku Wakil Kurikulum MTs Patra Mandiri Kota Palembang, via telepon, hari Senin tanggal 16 Maret 2020. Pukul 09.00 WIB.," 2020. 
i. Membawa dadah haram, membawa senjata tajam atau benda tumpul lain yang berbahaya. ${ }^{17}$

Melihat dari beberapa tata tertib yang diterapkan oleh MTs Patra Mandiri, kedisiplinan dan tanggung jawab atas diri sendiri dan lingkungan sangat ditekankan dan hal ini sejalan dengan harapan pemerintah yang tertera didalam Tujuan Nasional Indonesia.Sehingga harapannya proses pembelajaran dapat berjalan dengan baik tanpa adanya halangan apapun.

Selain dari tata tertib yang diterapkan, visi misi juga bagian dari perencanaan yang digunakan untuk keberlangsungan proses pelaksanaan pembelajaran agar mencapai hasil belajar yang maksimal. Visinya adalah Beriman, Berilmu, Terampil, Berkemasyarakatan sedangkan Misinya adalah 1) Menjalankan ibadah secara konsisten, 2) Menjalankan pembelajaran efektif, 3)Menjadikan siswa bebas dari buta aksara Al-Qur'an, 4) Mengaplikasikan potensi skill/berkarya, 5) Menjadikan siswa mampu bersaing dengan sekolah-sekolah lain, 6)Menjadikan siswa mampu berkiprah di tengah masyarakat secara baik serta Tujuan di MTs Patra Mandiri adalah untukMembentuk Insan Robbani menuju masyarakat Madani. ${ }^{18}$

Masyarakat madani merupakan jelmaan dari pembinaan bahasa "Islam" yang merujuk kepada kata al din, yang secara umum diterjemahkan sebagai agama, yang berkaitan dengan makna altamaddun, atau peradaban. Kedua-dua mereka bergabung menjadi makna al madinah yang bermaksud kota. Oleh itu, terjemahan

${ }^{17}$ Dokumen Patra Mandiri yang dikirimkan oleh Dra. Hj. Asnah HN selaku Wakil Kurikulum MTs Patra Mandiri Kota Palembang,via telepon, hari Senin tanggal 16 Maret. Pukul 12.00 WIB

${ }_{18}$ Dokumen Patra Mandiri yang dikirimkan oleh Dra. Hj. Asnah HN, "Selaku Wakil Kurikulum MTs Patra Mandiri Kota Palembang,via telepon, hari Senin tanggal 16 Maret. Pukul 12.00 WIB," 2020. 
masyarakat madani mengandungi tiga perkara, iaitu agama, peradaban dan kawasan bandar. Di sini agama adalah sumbernya, peradaban adalah prosesnya, dan masyarakat bandar adalah hasilnya. ${ }^{19}$

Mengacu pada bertujuan Pendidikan nasional, yakni untuk pengembangan pelajar menjadi manusia yang percaya dan takut kepada Tuhan Yang Maha Esa dan berakhlak mulia, objektif yang dinyatakan dalam MTs Patra Mandiri sangat relevan dengan pencapaian tujuan pendidikan nasional Indonesia.

Selain perencanaan mengenai tat tertib, visi misi serta tujuan, perencanaan pembelajaran MTs Patra Mandiri juga dirancang dalam bentuk Rancangan Pelaksanaan Pembelajaran (RPP) yang merujuk kepada Standard Proses. Dalam Permendiknas No. 41 tahun 2007 bertarikh 23 November 2007 mengenai proses standard untuk unit pendidikan rendah dan menengah, pengembangan RPP dijelaskan dari silibus untuk mengarahkan aktiviti pembelajaran pelajar dalam usaha mencapai Kompetensi Asas (KD). RPP disiapkan untuk setiap KD yang dapat dilaksanakan dalam satu atau lebih mesyuarat. Guru merancang rancangan pelajaran untuk setiap perjumpaan yang disesuaikan dengan jadual pelajaran di unit pendidikan. ${ }^{20}$

MTs Patra Mandiri adalah Madrasah Tsanawiyah yang memiliki manajemen kurikulum yang baik. Dalam perencanaan kurikumnya terstruktur dengan baik. Penyusunan program tahunan dan semesternya, pembuatan silabus serta pembuatan Rencana

${ }^{19}$ Eko Nursalim, “Pendidikan Islam Menuju Masyarakat Madani di Era Globalisasi (Suatu Ikhtiar Menghadapi Tantangan Masyarakat Ekonomi Asean/MEA)," Jurnal At-Turats 10, no. 1 (2016): 43 - 51.

${ }^{20}$ Masnur Muslich, Pembelajaran Berbasis Kompetensi dan Kontekstual, cet. 2 (Jakarta: Bumi Aksara, 2007). 
Pelaksanaan Pembelajaran (RPP) dirancang sebaik mungkin untuk memudahkan kegiatan belajar mengajar di madrasah. Semua pelaksanaan yang telah tercantum di kurikulum, silabus dan RPP langsung diimplementasikan kedalam kegiatan belajar mengajar siswa, misalnya pelaksanaan aktiviti penilaian dalam setiap mata pelajaran, pelaksanaan aktiviti pengayaan untuk pelajar yang telah mencapai kelengkapan pembelajaran, pelaksanaan aktiviti pemulihan untuk pelajar yang belum selesai, melaksanakan kad laporan bulanan dan melaksanakan mencuba untuk melihat hasil yang diperoleh oleh siswa disetiap prosesnya.

\section{Pelaksanaan Pembelajaran}

Pelaksanaan pembelajaran memiliki beberapa tujuan untuk mencapai tujuan dan hasil yang maksimal, antaranya ialah 1) mempermudah, mempercepat dan meningkatkan hasil proses pengajaran dan pembelajaran, 2) memberi peluang kepada pendidik merancang pembelajaran sesuai dengan keperluan pelajar, kemampuan pendidik dan kemudahan yang dimiliki oleh sekolah, 3) dengan menyusun rancangan pembelajaran yang profesional, sistematik dan berdaya maju menggunakan, guru akan dapat melihat, memerhati, menganalisis, dan meramalkan program pembelajaran sebagai kerangka yang logik dan terancang. ${ }^{21}$

Hasil wawancara dengan Innis Mala Dewi bahwa pelaksanaan pembelajaran di MTs Patra Mandiri yaitu:

"peserta didik yang ikut bergabung dalam kegiatan belajar mengajar cukup baik. Mereka melakukan pengamatan atau penyelidikan dengan serius, meskipun masih ada beberapa siswa yang harus ditegur dulu baru mau memperhatikan dan saya pikir itu adalah hal yang wajar. Mereka membaca dan mendengar dengan aktif, meskipun kita sebagai Guru harus lebih aktif membimbing mereka agar mereka

${ }^{21}$ Lukmanul Hakim, Perencanaan Pembelajaran (Bandung: CV Wacana Prima, 2009). 
tidak merasa bosan dan monoton dalam proses pembelajaran agar bisa semuanya tercapai tujuan pembelajaranya"22

Dalam pelaksanaan pembelajaran MTs Patra Mandiri menggunakan model kurikulum padat, iaitu pemadatan jirim dan masa. Dari segi menilai semua pembelajaran di Gunung Patra Mandiri, semua masalah mempunyai kaitan dengan kompetensi asas. Oleh itu, soalan-soalan ini dapat dijadikan alat pengukur untuk melihat pencapaian objektif pembelajaran. Walau bagaimanapun, beberapa soalan belum sepenuhnya memenuhi tuntutan objektif pembelajaran kerana alat penilaian yang digunakan adalah berbentuk ujian objektif. Penilaian proses dan / penilaian produk dilakukan dalam proses pengajaran-pembelajaran (: bukan pada peperiksaan akhir semester). Walau bagaimanapun, penilaian proses dan / produk tidak dapat dilakukan dengan teratur kepada pelajar kerana kesuntukan masa. Berdasarkan skor pelajar dalam peperiksaan akhir semester, tujuan pembelajaran di MTs Patra Mandiri telah tercapai.

Karakteristik setiap peserta didik memanglah berbeda-beda, mereka juga memiliki perbedaan latar belakang sebelum masuk dan bergabung di MTs Patra Mandiri Kota Palembang. Sesuai dengan Undang-undang RI No. 14 Tahun 2005 Tentan Guru dan Dosen terdapat 5 syarat menjadi guru yang profesional, diantaranya 1) memiliki kualifikasi akademik, 2) memiliki kompetensi, 3) memiliki setifikat pendidik, 4) sehat jasmani dan rohani dan 5) memiliki kemampuan untuk mewujudkan tujuan pendidikan nasional. ${ }^{23}$

${ }^{22}$ Hasil wawancara Hj. Innis Mala Dewi, Selaku Guru mata pelajaran Fikih MTs Patra Mandiri Kota Palembang,via telepon, hari Selasa tanggal 17 Maret. Pukul 11.00 WIB., 2020.

${ }_{23}$ Undang-Undang Republik Indonesia No. 14 tahun 2005 tentang Guru dan Dosen, Undang-Undang Republik Indonesia No. 14 tahun 2005 tentang Guru dan Dosen, issued 2005. 
Berangkat dari point ke-5, guru diharapkan memiliki kemampuan untuk mewujudkan tujuan pendidikan nasional, tentu hal ini telah dijalankan oleh guru-guru yang berada di MTs Patra Mandiri Kota Palembang agar proses pembelajaran didalam kelas tetap kondusif sehingga materi pembelajaran dapat diserap dengan mudah oleh peserta didik.

Dalam hal ini, guru berperan dalam pembentukan pendidikan karakter siswa, dimana pendidikan karakter sebagai proses yang terjadi secara sengaja, direncanakan, didesain dan diorganisasi berdasarkan perundang-undangan yang dibuat, misalnya Undangundang Nomor 20 Tahun 2003 tentang Sistem Pendidikan Nasional yang merupakan dasar penyelenggaraan pendidikan. ${ }^{24}$

Kurikulum yang digunakan dalam MTs Patra Mandiri menggunakan K 13. Meskipun dalam implementasinya terdapat beberapa kesulitan. Hal ini terlihat pada percakapan antara peneliti dengan kepala madrasah Patra Mandiri

"Patra Mandiri menggunakan Kurikulum 2013. Kami sebagai guru dituntut untuk memberikan ruang gerak terhadap peserta didik agar mereka bisa mengeksplor lebih banyak pengetahuan secara mandiri, tetapi sesekali kami masih memberikan materi menggunakan metode ceramah karena peserta didik perlu mendapatkan pengantar bagi kami untuk mendapatkan beberapa informasi, setelah itu barulah kita lepaskan mereka untuk dapat aktif dan mencari sebanyakbanyaknya informasi secara mandiri" 25

Dalam proses pembelajaran, pelajar tidak dapat diperlakukan sama oleh pendidik. Ini bermaksud bahawa pendidik tidak boleh mengabaikan perbezaan ciri setiap pelajar. Secara semula jadi, pelajar mempunyai watak yang unik, iaitu mempunyai kepelbagaian individu

${ }^{24}$ Fatchul Mu'in, Pendidikan Karakter: Konstruksi Teoritik dan Praktik (Jogjakarta: Ar-Ruzz Media, 2011).

${ }^{25}$ Hasil wawancara Drs. Abdul Kadir, "Selaku kepala madrasah MTs Patra Mandiri Kota Palembang,via telepon, hari Selasa tanggal 17 Maret. Pukul 11.00 WIB.," 2020. 
antara satu sama lain dalam pelbagai cara. Kepelbagaian ini boleh berupa kepelbagaian kecerdasan, bakat, keperibadian, dan keadaan fizikal. Dari segi kepelbagaian kecerdasan misalnya, setiap pelajar mempunyai kecerdasan yang berbeza. Perbezaan ini mesti ditangani dengan bijak, iaitu dengan memberikan rawatan mengikut bahagian pelajar.

Menurut Mooij, kanak-kanak berbakat mempunyai bidang minat yang berbeza, proses berfikir, dan cara bekerja dengan anakanak lain. Akibat perbezaan pengetahuan / ciri kognitif, dia juga mempunyai minat dan motivasi yang berbeza dari anak-anak lain. Berdasarkan kepelbagaian ciri-ciri ini, perlu memikirkan model pendidikan yang memudahkan perkembangan pelajar mengikut ciri masing-masing, termasuk pelajar yang mempunyai kebolehan dan bakat khas yang unggul. ${ }^{26}$

Dalam mencapai tujuan pendidikan, MTs Patra Mandiri menggunakan Kurikulum 2013. Guru-guru telah menggunakan pendekatan Active Learning, namun bukan semata-mata mereka tidak menjelaskan atau memberi penghantar bagi peserta didik untuk memperjelas dari materi yang sedang dipelajari sehingga Mix Method digunakan dalam penyampaian materi dengan harapan tujuan dan hasil belajar pun dapat tercapai dan dapat direalisasikan dalam kehidupan bermasyarakat.

Untuk melihat bagaimana perkembangan mix method ini, peneliti juga mencoba membandingkan dengan pernyataan dari salah satu siswa MTs Patra Mandiri yang sekarang sedang berada di kelas 2

26 Agnes Tri Harjaningrum, Peranan Orang Tua dan Praktisi dalam Membantu Tumbuh-kembang Anak Berbakat melalui Pemahaman Teori dan Tren Pendidikan (Jakarta: Prenada Media Group, 2011). 
MTs atau kelas 8. Siswa tersebut bernama Imam Santoso yang berada dikelas $8 \mathrm{~B}$.

"ketika saya masuk ke MTs ini memang sudah menggunakan kurikulum 2013. Proses pembelajarannya pada dasarnya sama saja dengan pembelajaran yang lain, hanya saja terkadang kami diminta untuk berdiskusi dan presentasi dan semua anggota kelas wajib untuk menanggapi. Tak jarang juga kami diberi waktu untuk mengamati lingkungan sekitar untuk dijadikan bahan diskusi. Hal ini membuatkami bekerjasama dalam mencari masalah, kerja team sangat diperlukan lalu kami kerjakan semua tugasnya secara bersama hingga akhirnya kami bisa menyelsaikan tugasnya dengan maksimal. Hal ini tidak membuat kami bosan tidak hanya mendengarkan saja didalam kelas. "27

Menarik kesimpulan pada wawancara yang peneliti lakukan pada salah satu siswa MTs tersebut. Beberapa aspek yang tertera didalam tujuan pendidikan berada didalam unsur-unsur pembelajaran mereka. Hal ini guna untuk menghasilkan hasil yang baik. Sehingga tujuan pendidikan ini snagat berpengaruh terhadap hasil belajar siswa.

\section{Evaluasi}

Evaluasi bukan hal yang asing dalam kehidupan masa sekarang, apalagi dalam dunia pendidikan. Educational evaluation is an assessment / assessment of students' growth and progress towards the goals or values set in the curriculum. Evaluasi sangat diperlukan untuk mengukur keberhasilan suatu lembaga terkhususnya didunia pendidikan. ${ }^{28}$

MTs Patra Mandiri evaluasinya dilakukan secara berkala artinya setiap menyelesaikan satu materi tertentu maka peserta didik harus diberikan soal-soal ataupun kegiatan praktek agar dapat melihat bagaimana perkembangan yang diperoleh peserta didik setelah proses

27 Hasil wawancara Imam Santoso, "Siswa kelas 8B MTs Patra Mandiri Kota Palembang, via telepon, hari Selasa tanggal 17 Maret. Pukul 14.00 WIB.," n.d.

${ }_{28}$ Sudaryono, Dasar - dasar Evaluasi Pembelajaran (Yogyakarta: Graha Ilmu, 2012). 
pembelajaran berlangsung. Hal ini sangat ditekankan karena hasil belajar siswa sangat diperlukan untuk melihat ketercapain tujuan pendidikan Nasional.

Dalam proses pembalajaran di sekolah, kegiatan pertanggung jawaban setiap peserta didik juga ditekankan melalui presentasi maupun langsung dipertanyakan oleh guru kelas. Selain itu pengevaluasian peserta didik tidak hanya dilihat dari ujian lisan maupun tertulisnya saja, melainkan dinilai melalui akhlak atau sikapsikap peserta didik terhadap guru maupun teman-teman sejawatnya. Sehingga pada proses pengevaluasian MTs Patra Mandiri meniali tiga aspek dalam penilaian yaitu aspek kognitif, aspek afektif dan aspek psikomotorik.

Berangkat dari uraian diatas, tujuan pendidikan sangat penting untuk menjadi acuan dari pada terselenggaranya proses penddidikan. Meskpun setiap lembaga memiliki tujuan yang spesifik dalam membentuk karakter peserta didik, namun tujuan pendidikan yang telah disahkan oleh pemerintah sangat memberikan peran yang besar dalam menghasilkan hasil belajar yang baik terhadap peserta didik.

\section{PEMBAHASAN}

\section{A. Tujuan Pendidikan Nasional}

Tujuan pendidikan adalah hal yang mungkinsudah familiar didengar oleh masyarakat awam, meskipun dalam implementasinya memiliki waktu dan usaha yang cukup besar. Seperti yang tertera didalam UUD No 20 tahun 2003, tujuan pendidikan adalah menciptakan manusia yang berakhlak mulia, cerdas, mampu berkarya, berkepribadian, berbudaya dan bermasyarakat yang beriimpllikasi bahwa dalam pengembangan potensi peserta didik 
melihat dimensi keberagaman, moralitas, sosialitas dan kebudayaan secara menyeluruh. Dalam hal ini, pendidikan memiliki fungsi sebagai memanusiakan manusia.

Standards mandated for teacher programs assist instructors who teach courses of study and provide keys, guidelines or instructions on the best ways to teach students the required knowledge and skill in a planned way to improve the quality of teaching and learning. ${ }^{29}$ Therefore, learning objectives that are derived from standards in teacher education are important for both instructors and students. Learning objectives help students to gain knowledge in a manner that takes them from simple to deep understanding. ${ }^{30}$ In other words, learning objectives provide both instructors and students with a roadmap of what they need for "know and where they are going and thenthey have arrived" before and during actual teaching practices. $^{31}$

Nasution menunjukkan setiap sekolah mendidik pelajar yang menjadi anggota masyarakat yang berguna bagi bangsa dan negara yang sebenarnya menunjukkan pendidikan di sekolah lebih kerap tidak berkaitan dengan kehidupan nyata pada masa. Kurikulum yang digunakan lebih banyak terfokus pada bidang pengajian yang boleh

${ }^{29}$ Christopher Gordon dan Ray Debus, “Developing deep learning approaches and personal teaching efficacy within a preservice teacher education context," British Journal of Educational Psychology 72, no. 4 (2002): 483-511.

${ }^{30}$ Benjamin. S. Bloom, Taxonomy of educational objectives. In Handbook 1: Cognitive domain (New York: David McKay, 1956).

${ }^{31} \mathrm{R}$. Arends, Learning to teach $(8$ th ed.) (New York: McGraw-Hill International Edition, 2009). 
difikirkan logis, sistematis dan teori tambahan jadi tidak berkaitan dengan kehidupan sehari-hari anak didik. Apa yang dipelajari peserta didik hanya mengutamakan kepentingan sekolah semata, bukan secara totalitas membantu anak didik agar hidup lebih baik dan berkesan dalam masyarakat. ${ }^{32}$

The Objective Process of Student Learning should be used throughout the school year to help teachers plan backwards from the final vision for student success. This process helps drive conversations and collaborations between teachers, students, and evaluators periodically to ensure that teaching facilitates students' progress towards growth goals. ${ }^{33}$

Berbicara mengenai tujuan pendidikan, pada dasarnya tidak dapat dipisahkan dengan hasil belajar siswa. Karna pendidikan merupakan alat yang digunakan untuk manusia dalam memelihara lenajutan hidupnya, baik dalam individu maupun kelompok. Tujuan pendidikan juga merupakan tolak ukur dalam pembangunan potensi individu agar dapat digunakan sendiri dan sebagainya oleh masyarakat untuk menghadapi cabaran era yang sentiasa berubah. ${ }^{34}$

Tujuan pendidikan di Indonesia selalu terdapat pembaharuan sesuai dengan zaman dan sesuai kebutuhan. Tujuan pendiidkan mengalami beberapa kali perubahan. Berikut beberapa tahapantahapan perubahan daripada tujuan pendidikan di Indonesia:

32 S. Nasution, Sosiologi Pendidikan (Jakarta: Bumi Aksara Pers, 2009).

33 Student Learning Objectives dan Additional Slo, Teachers Implementation Guide to Student Learning Objectives (Texas: Texas Education Agency, 2017).

${ }^{34}$ Hasan Langgulung, Peralihan Paradigma Pendidikan Islam dan Sains Sosial (Jakarta: Gaya Media Pratama, 2002). 
1. Pada Mukadimah UUD 1945

2. Rumusan mengikut Keputusan Menteri Pendidikan, Pengajaran dan Kebudayaan No. 104 / Bhg. O bertarikh 11 Mac 1946

3. Menurut Undang-undang No. 4 tahun 1950 (Undang-undang Pendidikan dan Pengajaran)

4. Menurut Keputusan MPRS Bilangan II Tahun 1960

5. Menurut Sistem Pendidikan Nasional Pancasila dengan Keputusan Presiden No. 19 tahun 1965

6. Menurut Keputusan MPRS No. XXVII 1966 Bab II artikel 3

7. Menurut Keputusan MPR Nombor IV / MPR / 1973 tentang GBHN

8. Menurut TAP MPR Nombor IV / MPR / 1978 mengenai GBHN Bab IV D

9. Menurut Keputusan MPR Nombor II / MPR / 1983 tentang GBHN

10. Menurut Keputusan MPR Nombor II / MPR / 1988 tentang GBHN

11. Menurut Undang-Undang Nomor 2 tahun 1989 tentang Sistem Pendidikan. ${ }^{35}$

Berubahnya perumusan tujuan pendidikan tersebut disesuaikan dengan bagaimana perkembangan dunia pendidikan pada saat itu. Keberhasilan pendidikan sangat ditekankan mengenai perubahan yang didapatkan oleh peserta didik setelah melaksanakan pembelajaran. Keberhasilan pada hal ini dapat dilihat mengenai hasil belajar yang diperoleh peserta didik.

\section{B. Penyelenggaraan Tujuan Pendidikan Nasional}

Indonesia merupakan Negara Kesatuan yang memiliki keberagaman suku, agama, ras, budaya, bahasa, maupun adat istiadat yang sama-sama melaksanakan pendidikan yang diatur didalam Undang-Undang No 20 Tahun 2003 pada pasal 4 yang, berbunyi:

a. Pendidikan dijalankan secara adil dan demokratik dan menjauhi sikap diskriminasi dengan menegakkan hak asasi manusia dan nilainilai pluralisme Bangsa.

35 Samsirin, "Titik Temu Tujuan Pendiidkan Islam dan Indonesia," Jurnal At'Ta'dib 13, no. 1 (2018): 67-92. 
b. Pendidikan diadakan sebagai unit sistematik dengan sistem terbuka dan pelbagai makna

c. Pendidikan diadakan sebagai proses sepanjang hayat memupuk dan memperkasakan pelajar

d. Pendidikan diadakan dengan membuat model, membina kehendak, dan mengembangkan kreativiti pelajar dalam proses pembelajaran

e. Pendidikan diadakan dengan mengembangkan budaya membaca, menulis dan aritmetik untuk semua anggota masyarakat

f. Pendidikan diadakan dengan memperkasakan semua komponen masyarakat melalui penyertaan dalam pelaksanaan dan pengendalian kualiti perkhidmatan pendidikan. ${ }^{36}$

Berdasarkan artikel ini, pendidikan di Indonesia tidak hanya menjadi tanggung jawab untuk melaksanakan institusi pendidikan atau sekolah, tetapi masyarakat dan pemerintah juga memiliki kepentingan dalam keberhasilan pendidikan nasional Indonesia. Dengan demikian pelaksanaan pendidikan di Indonesia akan memiliki output yang sesuai dengan kebutuhan masyarakat dan juga Negara.

\section{Pengertian Hasil Belajar}

Untuk memberi pemahaman tentang hasil pembelajaran, pertama akan dijelaskan dari segi bahasa. Hasil belajar terdiri daripada dua perkataan, iaitu "hasil" dan "belajar". Dalam KBBI hasil pembelajaran dapat ditafsirkan sebagai 1) sesuatu yang disediakan oleh perniagaan, 2) pendapatan; pemerolehan; buah. Sementara itu,

36 Wayan Cong Sujana, "Fungsi dan Tujuan Pendidikan Indonesia," Jurnal Adi Widya Pendidikan Dasar 4, no. 1 (2019): 29-39. 
pembelajaran adalah perubahan tingkah laku atau tindak balas yang disebabkan oleh pengalaman. ${ }^{37}$

Salah satu teori yang dibimbing adalah kerangka teori konstruktivis oleh Bruner pada tahun 1966. Ia berpendapat bahawa pembelajaran adalah proses aktif di mana pelajar membina idea atau konsep baru berdasarkan pengetahuan semasa dan masa lalu mereka dan bahawa pelajar memilih dan mengubah maklumat, membina hipotesis, dan membuat keputusan, bergantung pada struktur kognitif untuk melakukannya. Struktur kognitif (skema, model mental) memberikan makna dan organisasi kepada pengalaman dan membolehkan individu melampaui maklumat yang diberikan. Ini diperkukuhkan lagi oleh pandangan bahawa membina pengetahuan untuk diri sendiri membawa kepada pembelajaran dan penguasaan yang tulen. Johnston menjelaskan bahawa pembelajaran bukan mengenai pasif dan keteraturan; ini mengenai proses penemuan dan pembinaan pengetahuan yang tidak kemas yang membawa kepada pembelajaran dan penguasaan kandungan yang tulen. ${ }^{38}$

Abdurrahman menjelaskan bahawa hasil belajar ialah kebolehan yang diperoleh oleh anak-anak setelah melalui aktiviti pengajaran dan pembelajaran dan menurutnya, kanak-kanak yang berjaya dalam pembelajaran berjaya mencapai matlamat pembelajaran dan tujuan pendidikan negara. Hasil pembelajaran adalah kebolehan yang diperoleh oleh individu setelah proses pembelajaran

37 Tim Penyusun Kamus Pusat Bahasa, Kamus Besar Bahasa Indonesia (Jakarta: Balai Pustaka, 2007).

${ }^{38} \mathrm{P}$. Johnston, Choice words: How our language affects children's learning (Portland, ME: Stenhouse Publishers, 2004). 
berlangsung, yang dapat memberikan perubahan tingkah laku baik dalam pengetahuan, pemahaman, sikap dan kemahiran pelajar sehingga mereka menjadi lebih baik daripada sebelumnya. ${ }^{39}$

Ivan Illich believes that a good education system must have three purposes. The first is to give everyone the opportunity to be free and easy to get learning resources at any time. Second, this allows everyone to access education easily. Third, ensure the availability of general inputs related to education. ${ }^{40}$

Hasil pembelajaran adalah petunjuk proses pembelajaran. Hasil pembelajaran adalah perubahan tingkah laku yang diperoleh oleh pelajar setelah mengalami aktiviti pembelajaran. Salah satu petunjuk sama ada proses pembelajaran dicapai atau tidak adalah dengan melihat hasil pembelajaran yang dicapai oleh pelajar. Hasil pembelajaran adalah tahap penguasaan yang dicapai oleh pelajar dalam mengikuti program pengajaran dan pembelajaran, sesuai dengan objektif yang ditetapkan. ${ }^{41}$

Pandangan pembelajaran progresivisme bergantung pada pandangan pelajar sebagai makhluk yang mempunyai kelebihan berbanding makhluk lain. Di samping itu, penipisan tembok pemisah antara sekolah dan masyarakat menjadi asas untuk mengembangkan idea pendidikan progresivisme. Secara semula jadi pelajar sudah

${ }_{39}$ M. Ngalim Purwanto, Psikologi Pendidikan (Bandung: Remaja Rosda Karya, 2002).

${ }^{40}$ Aas Siti Sholichah, "Teori-Teori Pendidikan Dalam Al-Qur'an," Edukasi Islam, Jurnal Pendidikan Islam 07, no. 1 (2018): 23-46, doi:10.30868/EI.V7.

41 Catharina Tri Anni, Psikologi Belajar (Semarang: IKIP Semarang Press, 2004). 
mempunyai potensi akal dan kecerdasan. Dengan kecerdasan yang dinamik dan kreatif, pelajar mempunyai peruntukan untuk menghadapi dan menyelesaikan masalah yang ada. Berkaitan dengan semua itu, untuk meningkatkan kecerdasan dan kreativiti pelajar adalah tanggungjawab dunia pendidikan. ${ }^{42}$

Dalam Undang-undang Nomor 20 Tahun 2003 tentang Sistem Pendidikan Nasional dijelaskan bahwa:

"Pendidikan adalah usaha yang sedar dan terancang untuk mewujudkan suasana pembelajaran dan proses pembelajaran sehingga pelajar secara aktif mengembangkan potensi mereka untuk memiliki kekuatan spiritual agama, kawalan diri, keperibadian, kepandaian, akhlak mulia, dan kemahiran yang diperlukan oleh diri mereka sendiri, masyarakat, bangsa dan Negara". ${ }^{43}$

Seseorang yang telah melaksanakan proses pembelajaran dibuktikan dengan adanya suatu perubahan, misalnya dari yang tidak tahu menjadi tahu, dari tidak mengerti menjadi mengerti. ${ }^{44}$ Tingkah laku memiliki unsur subjektif dan unsur motoris. Unsure subjektif adalah unsur rohaniah sedangkan unsur motoris adalah unsure jasmaniah. Suatu perbuatan manusia memiliki sejumlah aspek yang memperkuatnya. Hasil belajar akan tampak pada setiap perubahan pada aspek-aspek tersebut. Adapun aspek-aspek diantaranya adalah:

42Siti Mustaghfiroh, "Konsep ' Merdeka Belajar' Perspektif Aliran Progresivisme Jgon Dewey," Jurnal Studi Guru dan Pembelajaran 3, no. 1 (2020): 141-47.

43 Undang-undang Nomor 20 Tahun 2003 tentang Sistem Pendidikan Nasional, "undang-undang Nomor 20 Tahun 2003 tentang Sistem Pendidikan Nasional," n.d.

44 Ahmad Wahyu Hidayat, "Pengembangan Dan Implementasi Kurikulum Pendidikan Agama Islam di SDN Demangan Yogyakarta," TARBIYATUNA 9, no. 2 (n.d.): 82-98. 
1. Pengetahuan

2. Memahami

3. Tabiat (kebiasaan)

4. Kemahiran

5. Penghargaan

6. Emosi

7. Hubungansosial

8. Jasmani

9. Beretika

10. Sikap. ${ }^{45}$

Jika dilihat dari beberapa aspek perubahan tingkah laku anak yang telah melaksanakan pembelajaran terdapat sinkronisasi dengan tujuan pendidikan yang tertera didalam UUD No. 20 tahun 2003. Hanya saja diperlukan pengamatan yang lebih lanjut apakah aspekaspek hasil belajar ini dapat terealisasi dengan baik atau tidak didalam MTs Patra Mandiri.

\section{Faktor-faktor yang dapat Mempengaruhi Hasil Belajar}

Sebagai proses keagungan belajar ditentukan oleh pelbagai faktor. Menurut Ryan, terdapat tiga faktor yang mempengaruhi hasil pembelajaran, iaitu: (1) aktiviti individu ketika berinteraksi dengan persekitaran; (2) faktor fisiologi individu; dan (3) faktor persekitaran yang terdiri daripada semua perubahan yang berlaku di sekitar individu.

Hasil peneliitian Florence Kanorio Kisirkoi \& Godfrey Mse menemukan bahwa pendekatan belajar mengajar yang digunakan di kelas oleh sebagian besar guru berpusat pada guru dan mendorong pembelajaran hafalan sehingga tidak mengikut sertakan pelajar secara aktif dalam proses pembelajaran berlangsung. Direkomendasikan 2004).

45 Oemar Hamalik, Proses Belajar Mengajar (Jakarta: PT. Bumi Aksara, 
bahwa harus ada kegiatan pengembangan profesional guru berbasis sekolah yang berkelanjutan yang secara khusus menangani pedagogi untuk peningkatan implementasi kurikulum dan pada akhirnya meningkatkan hasil pembelajaran. ${ }^{46}$

Faktor-faktor fisiologis yang mempengaruhi belajar mencakup dua hal, yaitu:

3. Keadaan jasman umum. Keadaan jasman mempengaruhi kesediaan dan aktiviti pembelajaran. Orang yang segar secara fizikal akan bersedia dan aktif dalam pembelajaran.

4. Keadaan fungsi fisiologi tertentu, terutama kesihatan deria, yang akan mempengaruhi pembelajaran yang mengakibatkan hasil pembelajaran yang buruk.

Faktor-faktor psikologis yang mempengaruhi belajar: ${ }^{47}$

a) Minat, minat terhadap objek yang dikaji akan mendorong orang untuk belajar sesuatu dan mencapai hasil pembelajaran yang maksimum.

b) Motivasi, motivasi belajar seseorang akan menentukan hasil pembelajaran yang mereka capai, iaitu Intelligence, yang merupakan modal utama dalam menjalankan aktiviti pembelajaran dan mencapai hasil pembelajaran yang maksimum. Orang yang mempunyai kecerdasan rendah tidak mungkin akan mencapai hasil pembelajaran yang lebih tinggi daripada orang yang mempunyai kecerdasan tinggi. Ingatan, iaitu kemampuan merekod, menyimpan,

${ }^{46}$ Florence Kanorio Kisirkoi dan Godfrey Mse, "Curriculum Implementation: Strategies for Improved Learning Outcomes in Primary Schools in Kenya," Journal of Curriculum and Teaching 5, no. 1 (2016): 19-26, doi:10.5430/jct.v5n1p19.

47 Nyayu Khodijah, Psikologi Pendidikan (Jakarta: Rajawali Pers, 2017). 
dan menyatakan kembali apa yang telah dipelajari akan sangat membantu dalam proses pembelajaran.

Faktor-faktor sosial, meliputi:

1) Orang Tua memainkan peranan penting dalam pembelajaran anakanak. Corak keibubapaan, kemudahan pembelajaran, perhatian, dan motivasi adalah sokongan pembelajaran yang mesti diberikan oleh ibu bapa untuk kejayaan pembelajaran anak-anak.

2) Guru, terutamanya kecekapan peribadi dan profesional guru, sangat mempengaruhi proses pembelajaran dan hasil yang dicapai oleh pelajar.

3) Rakan atau orang di sekitar persekitaran pembelajaran, kehadiran orang lain secara langsung atau tidak langsung boleh memberi kesan yang baik atau buruk kepada pembelajaran seseorang, sama ada mendapat gred yang baik atau sebaliknya.

Hasil pembelajaran yang dicapai dalam proses pembelajaran adalah ukuran hasil usaha yang dilakukan oleh pendidik dan pelajar dengan semua faktor yang berkaitan. Terdapat perbezaan tahap kejayaan antara satu institusi pendidikan dengan institusi pendidikan yang lain, bahkan sekarang unit pendidikan diberi wewenang untuk dapat menentukan Kriteria Penyelesaian Minimum (KKM) secara individu walaupun proses dan faktornya sama.

\section{KESIMPULAN}

Dalam pelaksanaan pembelajaran MTs Patra Mandiri menggunakan model kurikulum ringkas, yaitu pemadatan bahan dan masa. Dari segi menilai semua pembelajaran di Gunung Patra Mandiri, semua masalah mempunyai kaitan dengan kompetensi asas. 
Oleh itu, soalan-soalan ini dapat dijadikan alat pengukur untuk melihat pencapaian objektif pembelajaran. Walau bagaimanapun, beberapa soalan belum sepenuhnya memenuhi tuntutan objektif pembelajaran karena alat penilaian yang digunakan adalah berbentuk ujian objektif. Penilaian proses dan / penilaian produk dilakukan dalam proses pengajaran-pembelajaran (: bukan pada peperiksaan akhir semester). Walau bagaimanapun, penilaian proses dan / produk tidak dapat dilakukan dengan teratur kepada pelajar kerana kesuntukan masa. Berdasarkan skor pelajar dalam peperiksaan semester akhir, objektif pembelajaran di MTs Patra Mandiri telah dicapai. Hasilnya pelajar yang mengambil bagian dalam aktivitas pengajaran dan pembelajaran cukup baik. Mereka memandang kepada pemerhati proses belajar, walaupun masih ada beberapa pelajar yang harus ditegur terlebih dahulu sebelum mereka ingin memberi perhatian itu merupakan perkara yang wajar. Mereka membaca dan mendengar secara aktif, walaupun kita sebagai guru harus lebih aktif membimbing siswa agar tidak merasa bosan dan monoton dalam proses pembelajaran sehingga semua tujuan pembelajaran yang ingin di capai.

\section{DAFTAR PUSTAKA}

Agustanti, T H. “Implementasi Metode INquiry untuk meningkatkan Hasil Belajar Biologi." Jurnal Pendidikan IPA Indonesia 1, no. 1 (2012): 16-20.

Al-shammari, Zaid. "Implementation Of Standards-Based, Learning Objectives-Enhanced Student Learning And Achievement Via 
A Designed Analysis Model For Learning Outcomes ( Amlo ) In A Teacher Education Program In Kuwait: A Preliminary Analysis" 16, no. 1 (2006): 1-5.

Anni, Catharina Tri. Psikologi Belajar. Semarang: IKIP Semarang Press, 2004.

Arends, R. Learning to teach(8th ed.). New York: McGraw-Hill International Edition, 2009.

Arifin, Zainal. Pengembangan Managemen Mutu Kurikulum Pendidikan Islam. Cet. I. Yogyakarta: DIVA Press, 2012.

Bloom, Benjamin. S. Taxonomy of educational objectives. In Handbook 1: Cognitive domain. New York: David McKay, 1956.

Bungin, Burhan. Penelitian Kualitatif. Jakarta: Kencana, 2007.

Debus, Christopher Gordon dan Ray. "Developing deep learning approaches and personal teaching efficacy within a preservice teacher education context." British Journal of Educational Psychology 72, no. 4 (2002): 483-511.

Dkk, Sa'ud. Perencanaan pendidikan. Bandung: PT. Remaja Rosdakarya, 2014.

Dosen, Undang-Undang Republik Indonesia No. 14 tahun 2005 tentang Guru dan. Undang-Undang Republik Indonesia No. 14 tahun 2005 tentang Guru dan Dosen, issued 2005.

Hakim, Lukmanul. Perencanaan Pembelajaran. Bandung: CV Wacana Prima, 2009.

Hamalik, Oemar. Proses Belajar Mengajar. Jakarta: PT. Bumi Aksara, 2004.

Harjaningrum, Agnes Tri. Peranan Orang Tua dan Praktisi dalam 
Membantu Tumbuh-kembang Anak Berbakat melalui Pemahaman Teori dan Tren Pendidikan. Jakarta: Prenada Media Group, 2011.

Hasil wawancara Drs. Abdul Kadir. “Selaku kepala madrasah MTs Patra Mandiri Kota Palembang,via telepon, hari Selasa tanggal 17 Maret. Pukul 11.00 WIB.," 2020.

Hasil wawancara Hj. Innis Mala Dewi. Selaku Guru mata pelajaran Fikih MTs Patra Mandiri Kota Palembang,via telepon, hari Selasa tanggal 17 Maret. Pukul 11.00 WIB., 2020.

Hasil wawancara Imam Santoso. "Siswa kelas 8B MTs Patra Mandiri Kota Palembang,via telepon, hari Selasa tanggal 17 Maret. Pukul 14.00 WIB.," n.d.

Hidayat, Ahmad Wahyu. "Pengembangan Dan Implementasi Kurikulum Pendidikan Agama Islam di SDN Demangan Yogyakarta." TARBIYATUNA 9, no. 2 (n.d.): 82-98.

HN, Dokumen Patra Mandiri yang dikirimkan oleh Dra. Hj. Asnah. “Selaku Wakil Kurikulum MTs Patra Mandiri Kota Palembang,via telepon, hari Senin tanggal 16 Maret. Pukul $12.00 \mathrm{WIB}, " 2020$.

HN, Hasil wawancara dengan Dra. Hj. Asnah. "selaku Wakil Kurikulum MTs Patra Mandiri Kota Palembang, via telepon, hari Senin tanggal 16 Maret 2020. Pukul 09.00 WIB.," 2020.

Johnston, P. Choice words: How our language affects children's learning. Portland, ME: Stenhouse Publishers, 2004.

Khodijah, Nyayu. Psikologi Pendidikan. Jakarta: Rajawali Pers, 2017. Kisirkoi, Florence Kanorio, dan Godfrey Mse. "Curriculum Implementation: Strategies for Improved Learning Outcomes in 
Primary Schools in Kenya." Journal of Curriculum and Teaching 5, no. 1 (2016): 19-26. doi:10.5430/jct.v5n1p19.

Langgulung, Hasan. Peralihan Paradigma Pendidikan Islam dan Sains Sosial. Jakarta: Gaya Media Pratama, 2002.

Mu'in, Fatchul. Pendidikan Karakter: Konstruksi Teoritik dan Praktik. Jogjakarta: Ar-Ruzz Media, 2011.

Munirah. "Sistem Pendidikan Di Indonesia: Antara Keinginan Dan Realita." Jurnal Auladuna 2, no. 2 (2015): 233-45.

Muslich, Masnur. Pembelajaran Berbasis Kompetensi dan Kontekstual. Cet. 2. Jakarta: Bumi Aksara, 2007.

Mustaghfiroh, Siti. “Konsep 'Merdeka Belajar' Perspektif Aliran Progresivisme Jgon Dewey." Jurnal Studi Guru dan Pembelajaran 3, no. 1 (2020): 141-47.

Nasution, S. Sosiologi Pendidikan. Jakarta: Bumi Aksara Pers, 2009.

Nursalim, Eko. “Pendidikan Islam Menuju Masyarakat Madani di Era Globalisasi (Suatu Ikhtiar Menghadapi Tantangan Masyarakat Ekonomi Asean/MEA)." Jurnal At-Turats 10, no. 1 (2016): 43 51.

Objectives, Student Learning, dan Additional Slo. Teachers Implementation Guide to Student Learning Objectives. Texas: Texas Education Agency, 2017.

Paolini, Allison. "Enhancing teaching effectiveness and student learning outcomes." The Journal of Effective Teaching 15, no. 1 (2015): 20-33. http://search.ebscohost.com/login.aspx?direct=true\&db=eue\&A $\mathrm{N}=102152590 \&$ site $=$ ehost-live\&scope $=$ site. 
Parwata, I Gusti Lanang Agung. "Penerapan Model Pembelajaran Langsung Berbantuan Media VCD Untuk Meningkatkan Aktivitas Dan Hasil Belajar Mahasiswa Pada Perkuliahan Atletik I." Penelitian dan Pengembangan Pendidikan 2, no. 1 (2008).

PURPOSE OF THE BRIEF. “Effective Coaching: Improving Teacher Practice and Outcomes for All Learners." WestEd 1, no. 1 (2005): 1-17. https://www.air.org/sites/default/files/NCSI_EffectiveCoaching-Brief-508.pdf.

Purwanto, M. Ngalim. Psikologi Pendidikan. Bandung: Remaja Rosda Karya, 2002.

Samsirin. “Titik Temu Tujuan Pendiidkan Islam dan Indonesia." Jurnal $A t^{\prime} T a^{\prime} d i b$ 13, no. 1 (2018): 67-92.

Sanjaya, Wina. Strategi Pembelajaran. Jakarta: Kencana, 2007.

Sholichah, Aas Siti. “Teori-Teori Pendidikan Dalam Al-Qur'an."

Edukasi Islam, Jurnal Pendidikan Islam 07, no. 1 (2018): 23-46. doi:10.30868/EI.V7.

Sudaryono. Dasar - dasar Evaluasi Pembelajaran. Yogyakarta: Graha Ilmu, 2012.

Sujana, Wayan Cong. "Fungsi dan Tujuan Pendidikan Indonesia." Jurnal Adi Widya Pendidikan Dasar 4, no. 1 (2019): 29-39.

Suprijono, Agus. Cooperative Learning: Teori \& Aplikasi Paikem. Yogyakarta: Pustaka Pelajar, 2009.

Susilodkk, Madyo Eko. Dasar-Dasar Pendidikan. Semarang: Effha, 2001. Tim Penyusun Kamus Pusat Bahasa. Kamus Besar Bahasa Indonesia. Jakarta: Balai Pustaka, 2007. 
Umar, Bukhari. Ilmu Pendidikan Islam. Jakarta: Amzah, 2011.

Undang-undang Nomor 20 Tahun 2003 tentang Sistem Pendidikan Nasional. "undang-undang Nomor 20 Tahun 2003 tentang Sistem Pendidikan Nasional," n.d.

Usman, H. Manajemen teori, praktik, dan riset pendidikan. Jakarta: PT. Bumi Aksara, 2008. 